\title{
RNAimmuno: A database of the nonspecific immunological effects of RNA interference and microRNA reagents
}

\author{
MARTA OLEJNICZAK, PAULINA GALKA-MARCINIAK, KATARZYNA POLAK, ANDRZEJ FLIGIER, \\ and WLODZIMIERZ J. KRZYZOSIAK ${ }^{1}$ \\ Laboratory of Cancer Genetics, Institute of Bioorganic Chemistry, Polish Academy of Sciences, 61-704 Poznan, Poland
}

\begin{abstract}
The RNAimmuno database was created to provide easy access to information regarding the nonspecific effects generated in cells by RNA interference triggers and microRNA regulators. Various RNAi and microRNA reagents, which differ in length and structure, often cause non-sequence-specific immune responses, in addition to triggering the intended sequence-specific effects. The activation of the cellular sensors of foreign RNA or DNA may lead to the induction of type I interferon and proinflammatory cytokine release. Subsequent changes in the cellular transcriptome and proteome may result in adverse effects, including cell death during therapeutic treatments or the misinterpretation of experimental results in research applications. The manually curated RNAimmuno database gathers the majority of the published data regarding the immunological side effects that are caused in investigated cell lines, tissues, and model organisms by different reagents. The database is accessible at http://rnaimmuno.ibch. poznan.pl and may be helpful in the further application and development of RNAi- and microRNA-based technologies.
\end{abstract}

Keywords: RNA interference; nonspecific effects; toxic effects; siRNA; interferon response

\section{INTRODUCTION}

RNA interference (RNAi) technology takes advantage of the natural pathways and protein factors to silence selected genes with the use of various exogenous reagents (Olejniczak et al. 2010). The RNAi process is efficiently triggered by short interfering RNAs (siRNAs) (Caplen et al. 2001; Elbashir et al. 2001; Yang et al. 2001; Kim et al. 2005; Amarzguioui et al. 2006), synthetic (McManus et al. 2002; Siolas et al. 2005) or vector-based short hairpin RNAs (shRNAs) (Paddison et al. 2002; Boudreau et al. 2008), or pri-miRNA-based expression cassettes (sh-miRs) (Zeng et al. 2002; Silva et al. 2005; Chang et al. 2006).

Deregulation of the cellular miRNA level has been shown to be associated with different types of diseases, including cancer. Therefore, the use of the spectrum of miRNA-based tools (Olejniczak et al. 2010) may allow for the increase of underexpressed miRNAs (e.g., miRNA mimetics) (Tsuda et al. 2009) or the decrease of overexpressed miRNAs (e.g., anti-miRs [Krützfeldt et al. 2005], miRNA sponges [Ebert et al. 2007; Ebert and Sharp 2010], decoys [Haraguchi et al.

\footnotetext{
${ }^{1}$ Corresponding author.

E-mail wlodkrzy@ibch.poznan.pl.

Article published online ahead of print. Article and publication date are at http://www.rnajournal.org/cgi/doi/10.1261/rna.025627.110.
}

2009], or target protectors [Choi et al. 2007]) in tumor tissues.

The tools of RNAi and microRNA technologies have been used successfully both in basic research to study the functions of specific proteins and miRNAs and in the experimental treatment of many human diseases. However, in addition to triggering sequence-specific effects, the reagents used in both technologies often stimulate cellular sensors of foreign RNA and DNA, which recognize patterns associated with pathogens (pathogen-associated molecular patterns, PAMPs) (Fig. 1; Marques et al. 2006; Reynolds et al. 2006; Robbins et al. 2008, 2009; Olejniczak et al. 2010). This effect depends mostly on the reagent length, structure, chemical modification, concentration, and cellular localization rather than on its specific sequence, which may be involved in off-target effects (Jackson et al. 2003; Fedorov et al. 2006). The first identified cellular sensors of foreign RNA were the IFN-inducible dsRNA-activated protein kinase (PKR) (Roberts et al. 1976) and $2^{\prime}-5^{\prime}$-oligoadenylate synthetase (OAS) (Farrell et al. 1978). It was reported that the full activation and dimerization of PKR is undertaken after binding $\sim 33$ bp of helical RNA, whereas PKR monomers are able to bind 16-18 bp of RNA (Manche et al. 1992; Bevilacqua and Cech 1996; Zhang et al. 2001). Additionally, blunt-ended dsRNAs with 5'-triphosphate were shown to activate PKR (Nallagatla et al. 2007). Activa- 


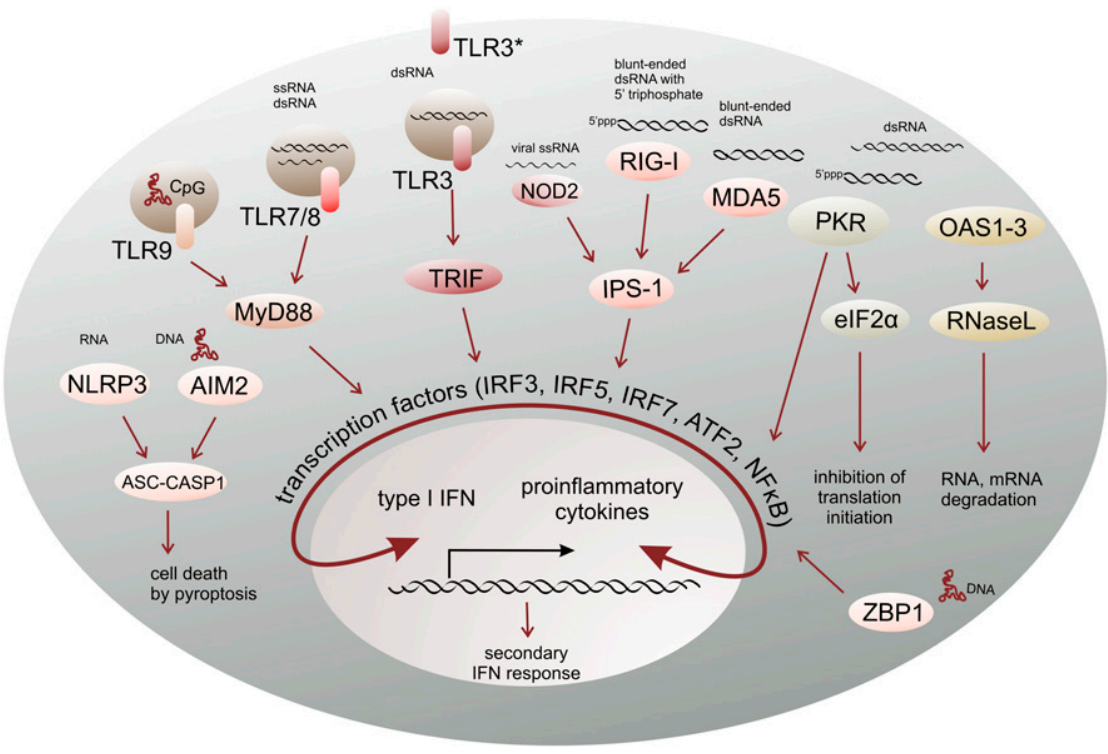

FIGURE 1. Reagents of RNAi and miRNA technologies delivered to cells either by transfection or released from expression vectors may be recognized by specific cellular sensors of foreign RNA and DNA. After the activation of cytoplasmic (RIG-I, MDA5, PKR, and OAS1-3) and endosomal (TLR3, 7, and 8) sensors, a signal is transduced through specific adaptor proteins to transcription factors which, in turn, stimulate production of proinflammatory cytokines and IFN. The activation of other sensors may induce cell death by pyroptosis (AIM2, NLRP3). TLR3 localization (denoted by asterisk) is cell type-dependent.

tion of the PKR and OAS signaling pathways by long dsRNA results in the general inhibition of protein synthesis and the degradation of cellular RNA, respectively. The other cytoplasmic sensors of foreign RNA in human cells are two helicases, retinoic acid inducible gene I (RIG-I) and melanoma differentiation associated gene-5 (MDA5). RIG-I recognizes blunt-ended dsRNA molecules with a $5^{\prime}$ triphosphate (5' ppp) that are over $20 \mathrm{bp}$ long (Schlee and Hartmann 2010), and MDA5 is activated by long dsRNA (Kang et al. 2002). Widely used reagent carriers composed of cationic lipids localize RNA to endosomal compartments, where it can be recognized by Toll-like receptors (TLR3, 7, and 8) (Alexopoulou et al. 2001; Heil et al. 2004; Gantier and Williams 2009). Some of these receptors are sensitive to specific RNA sequences; however, chemical modification of these immunostimulatory motifs may abrogate this effect (Sioud 2009). The other group of cellular sensors (TLR9, AIM2, and ZBP1) recognizes foreign DNA that has been introduced into cells either as a plasmid or through a viral vector. Less is known about the NLRP3 (Kanneganti et al. 2006) and NOD2 (Sabbah et al. 2009) sensors that belong to the nucleotide oligomerization domain (NOD)-like family of proteins (NOD-like receptors, NLRs) and recognize dsRNA and ssRNA, respectively.

The activation of cytoplasmic or endosomal sensors results in signal transduction through specific adaptor proteins to transcription factors, which, in turn, stimulate production of proinflammatory cytokines and interferons (IFNs). IFNs regulate the transcription of $\sim 2000$ genes in an IFN subtype-,

\section{RESULTS} section.

\section{Searching options}

dose-, cell type-, and stimulus-dependent manner (Samarajiwa et al. 2009). Changes in the cellular transcriptome and proteome, however, can lead to the inhibition of cell division and growth and eventually to apoptosis. In research applications, an additional undesired effect may be the misinterpretation of experimental results (Robbins et al. 2008). Because the data regarding the nonspecific effects of RNAi and miRNA technology are dispersed among numerous papers, we decided to gather all these data in the form of a widely accessible and comprehensive database. The RNAimmuno database provides an opportunity to analyze and compare the results of different studies and may help develop safer RNAi technology reagents. The name of the database is a combination of the words "RNAi" and "immunology" and simply reflects the contents of RNAimmuno. To our knowledge, this is the first database concerning the non-sequence-specific effects of RNAi and miRNA reagents.

\section{Database contents and web interface}

The goal of RNAimmuno is to collect the published data regarding the nonspecific immunological effects of reagents (e.g., siRNAs, shRNAs, sh-miRs, and anti-miRs) observed in investigated cell lines and model organisms. RNAimmuno is also designed to be the comprehensive source of knowledge regarding different aspects of these immunological off-target effects. Currently, the database contains more than 2000 records, most of which describe the effects caused by various siRNA reagents (Supplemental Fig. 1A). The lower number of records regarding other reagent types simply reflects the underrepresentation of the relevant data in published papers. The detailed statistics of the records that represent different categories of advanced search is shown in the Statistics

RNAimmuno may be searched either by entering a keyword in the "quick search" window or by choosing specific records from panels in the "advanced search." As a keyword, the user may enter a gene or protein symbol (e.g., PKR, TLR3, or IFN), reagent type (e.g., siRNA or shRNA), reagent carrier (e.g., Lipofectamine, DOTAP, or lentivirus), experimental model (e.g., HEK, HeLa, or mice), target gene, reagent ID number, or the name of the first author of a 
relevant publication. When using the "advanced search" option, the user specifies the reagent type, reagent carrier, experimental model, sensor or responder name, level of activation/induction, reagent sequence, immunostimulatory motif, or reagent modifications. As responders, we mean proteins from the activated pathway (e.g., transcription factors, cytokines, or chemokines) functioning downstream from cellular sensors recognizing foreign RNA or DNA. Additionally, there is the possibility to search records derived from selected papers by entering the name of the first author of the relevant publication in the "advanced search" panel. The main table of results contains data concerning reagent ID and its original name, experimental model, reagent carrier, level of induction/activation of foreign RNA sensors and responders, and the chemical modification of the reagent when specified. Particular records contain dropdown detailed information which includes reagent type, its sequence, length, end structure, origin, concentration, target gene, observed effects (raw data), and comments. Data which need additional comment are marked with asterisks.

We found it difficult to apply a universal scale of activation effects due to the use of different experimental conditions, methods of analysis, and biological systems by different authors (e.g., in vivo systems vs. in cell lines). Therefore, the scale we used to describe the observed effects, i.e., no activation/induction (-/mock), activation/induction (+/mock), and strong activation/induction $(++/$ mock), generally refers to the results described in specific publications (obtained in specific experimental conditions). Additionally, the activation status of the sensor or responder is presented as an activation/induction relevant to a specific control (up/ specific control, down/specific control, similar/specific control), and, wherever possible, the fold-change is also indicated. To avoid any misinterpretation of the results, the raw data from the original publications are also included. An example of possible search results is shown in the screenshot in Figure 2.

\section{RNAimmuno tools}

The database provides the user with tools that may be helpful in designing safer RNAi reagents. The "simple tool" option allows scanning the reagent of interest for the presence of the most important molecular patterns known to activate the cellular sensors of foreign RNA (immunostimulatory motifs, reagent's length, blunt end, and $5^{\prime}$ triphosphate). A more advanced "sequence alignment" tool uses the BLASTN algorithm (Altschul et al. 1990) to align input sequence with reagents collected in the RNAimmuno database. The results of a search are summarized in a simple tabular format of hits followed by alignments of the query sequence against each hit sequence. Detailed information

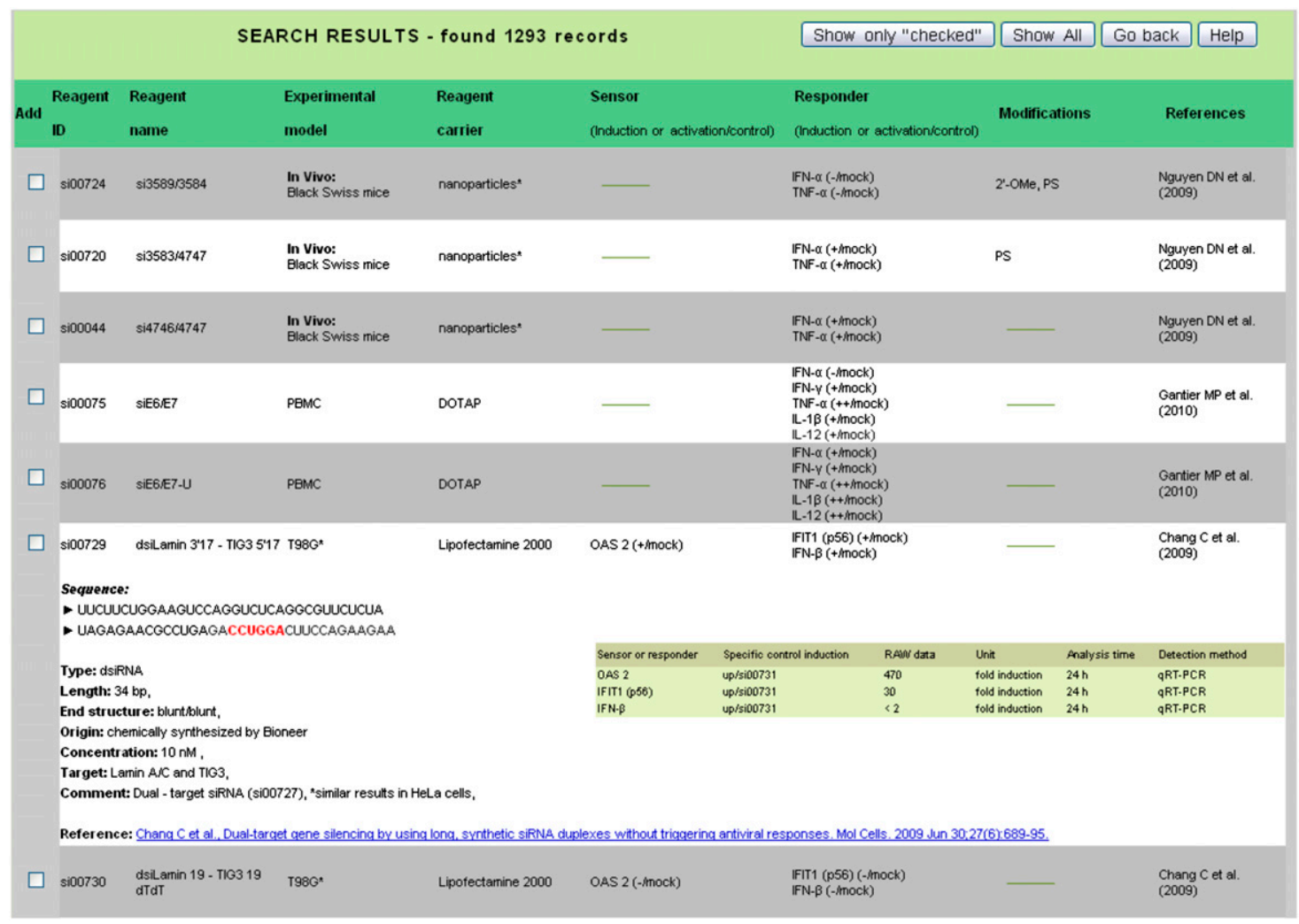

FIGURE 2. An example of search results. Detailed information about the selected reagent is available after clicking on a reagent (e.g., reagent si00729). The specified reagent sequence is highlighted in red. 
about the effects generated by reagents showing a high degree of similarity to the query sequence is accessible via specific links in the table.

\section{Pathways and sensors}

RNAimmuno also contains the most important information about the known cellular sensors of foreign RNA and DNA (SENSORS button) and the pathways these sensors mobilize (PATHWAYS button). This information is presented in tables with links to external public databases. These pages also provide information such as the gene and protein name, with aliases, HGNC ID, NCBI gene page, OMIM ID, NCBI transcript page, gene expression data, protein data, cellular localization of the sensor, type of ligand and adaptor protein, and the signal transduction pathway. For each sensor, the "references" link redirects the user to the PubMed database.

\section{Delivery/uptake}

Existing data have shown that the reagent carriers are not neutral to cells and may induce immune responses. Therefore, we gathered the published data regarding the toxicity of the transfection reagents frequently used in RNAi experiments (DELIVERY/UPTAKE button). Currently, this page includes information on 22 carriers used in the experiments described in the RNAimmuno database. The reagent carriers are characterized by their type and source and also by the type of reagent and cell line dedicated to transfection with the use of each specific carrier. In addition, the page contains links to the publications where the toxic effects of the reagent carriers were examined.

\section{DISCUSSION}

The RNAimmuno database was created to provide information regarding the nonspecific immunological effects of RNAi and miRNA reagents. Because data of this nature are dispersed among the numerous papers where RNAi and miRNA reagents are used, there is a need to gather these data sets in one location. In addition, there is a lack of clear guidelines on how to study immunological side effects, and the selection of immune response markers is left to researchers' decisions. RNAimmuno provides researchers with an opportunity to analyze and compare all these data. Statistical insight into RNAimmuno records shows that nonspecific immunological effects are predominantly analyzed through the measuring of the cytokine levels (ELISA and RT-PCR). Among them IFN $\alpha$, TNF $\alpha$, IFN $\beta$, and IL-6 account for more than $70 \%$ of all records (Supplemental Fig. 1B). OAS1, PKR, and RIG-I are the most frequently studied sensors, but their induction is typically analyzed with the use of the qRT-PCR method and microarrays. Since most of the sensors belong to the group of Interferon Stimulated Genes (ISGs), the observed increase of mRNA level may result from the secondary effect of IFN stimulation and should not be considered as the effect of direct activation of a specific sensor protein. We have also performed a more detailed analysis of types of sensors and responders studied in different experimental systems, classified into: immune cells (mostly PBMC and pDCs); nonimmune cells (mostly HEK and HeLa cells); and in vivo models (Supplemental Fig. 1C). Immunological side effects of RNAi triggers in vivo and in immune cells are mostly studied by measuring cytokine levels (IFN $\alpha$, TNF $\alpha$, and IL6), whereas in nonimmune cells more than 20 different inflammatory markers were studied. In addition to simple viability tests, IFN $\beta$, OAS1, IL-8, IL-6, STAT1, and IFIT1 analysis are also often performed (Supplemental Fig. 1C). Careful inspection of the gathered data clearly demonstrates that the analyses of the immunological side effects in nonimmune cells are often carried out in an incoherent way, and the current knowledge concerning sensors and their ligands is rarely taken under consideration.

A sample use of this database would be to check whether or not a reagent of interest, or similar reagents, delivered with the use of a selected carrier, activated the immune response in a specific experimental model. By the use of specific filtering options, it is possible to analyze the influence of various parameters (e.g., reagent type, sequence, concentration, and chemical modifications) on the activation/induction of specific cellular sensors and on cell viability. Users may also be able to find a less toxic reagent and experimental conditions (e.g., reagent concentration or delivery method) to silence the selected target gene. Among the delivery methods, cationic lipids account for the vast majority of records (e.g., Lipofectamine-38 papers, and DOTAP-22 papers) (Supplemental Fig. 1A). DOTAP is very often used as a reagent carrier in papers where TLR7/8 recruitment by RNAs containing immunostimulatory motifs was studied. Because reagent carriers may influence the expression level of many genes (Delivery/Uptake page), this possibility should be taken into account when interpreting experimental results.

The RNA reagents that strongly activate the immune system may also be desired in some studies (e.g., in antiviral and cancer therapy), and the database may be helpful in identifying such reagents. The RNAimmuno database also provides an opportunity to find appropriate control reagents that were characterized with regard to the induction of nonsequence-specific effects. The problem of using improper control siRNA in RNAi studies was already discussed (Robbins et al. 2008; Rossi 2009; Shukla et al. 2010). For example, siRNA targeting GFP, widely used as a negative control in RNAi studies, has extremely low immunostimulatory properties, whereas most other unmodified siRNAs can stimulate the innate immune response. There is a possibility that observed therapeutic effects may result from the activation of an immune response rather than from the RNA interference mechanism, as reported previously 
(Kleinman et al. 2008). Therefore, it is necessary to evaluate the contribution of the immune response in the final effect, especially in in vivo and clinical studies. RNAimmuno also contains ranking of the most commonly used siRNAs. The most frequently used EGFP siRNA was studied in 11 different papers and generated 144 records (due to different experimental conditions and reagent modifications).

RNAimmuno is targeted to a wide community of biologists, primarily bench scientists, and may be helpful in both the design of experiments and the interpretation of results. As new data are incorporated, RNAimmuno will provide opportunities for more comprehensive analysis of the immunological side effects of specific reagents. Currently, the database contains mostly data from in vitro experiments, but we anticipate an increased number of records with in vivo applications of RNAi and miRNA technologies in the future. We believe that widespread access to this database will hasten efforts to develop safer gene silencing technologies.

\section{MATERIALS AND METHODS}

\section{Implementation}

The RNAimmuno database v. 1.0 runs in a Linux environment, and it has been developed as a relational database in MySQL. The search engine is served by the Apache http daemon along with the PHP scripts. The interface component consists of the web pages designed and implemented in HTML/CSS. It has been tested in many web browsers, including Mozilla Firefox, Internet Explorer, Opera, Safari, and Google Chrome. The service is hosted and maintained by the Institute of Bioorganic Chemistry, Polish Academy of Sciences, Poznan, Poland.

\section{Submission of new data}

The usefulness of RNAimmuno depends on the amount of published data describing immunological side effects of RNAi and miRNA reagents. Therefore, it is very important to keep the database up to date with new data. Currently, it is not possible to update the database automatically; all relevant papers have to be carefully analyzed before new data can be introduced into the database. Data can be submitted to the database by contacting the database manager either through the submit form available for download or by e-mail. Detailed instructions for completion are contained in the form, which requires Excel or another compatible spreadsheet program. The data will then be evaluated and will be added to the database during the next update.

\section{SUPPLEMENTAL MATERIAL}

Supplemental material is available for this article.

\section{ACKNOWLEDGMENTS}

We thank Grzegorz Jankowiak for his help in the construction of the database. This work was supported by the Ministry of Science and Higher Education (N N301 284837, N302 633240) and the European Regional Development Fund within the Innovative Economy Programme (POIG.01.03.01-30-098/08).

Received November 26, 2010; accepted January 30, 2012.

\section{REFERENCES}

Alexopoulou L, Holt AC, Medzhitov R, Flavell RA. 2001. Recognition of double-stranded RNA and activation of NF- $\kappa \mathrm{B}$ by Toll-like receptor 3. Nature 413: 732-738.

Altschul SF, Gish W, Miller W, Myers EW, Lipman DJ. 1990. Basic local alignment search tool. J Mol Biol 215: 403-410.

Amarzguioui M, Lundberg P, Cantin E, Hagstrom J, Behlke MA, Rossi JJ. 2006. Rational design and in vitro and in vivo delivery of Dicer substrate siRNA. Nat Protoc 1: 508-517.

Bevilacqua PC, Cech TR. 1996. Minor-groove recognition of doublestranded RNA by the double-stranded RNA-binding domain from the RNA-activated protein kinase PKR. Biochemistry 35: 99839994.

Boudreau RL, Monteys AM, Davidson BL. 2008. Minimizing variables among hairpin-based RNAi vectors reveals the potency of shRNAs. RNA 14: $1834-1844$.

Caplen NJ, Parrish S, Imani F, Fire A, Morgan RA. 2001. Specific inhibition of gene expression by small double-stranded RNAs in invertebrate and vertebrate systems. Proc Natl Acad Sci 98: 97429747.

Chang K, Elledge SJ, Hannon GJ. 2006. Lessons from nature: MicroRNA-based shRNA libraries. Nat Methods 3: 707-714.

Choi W, Giraldez AJ, Schier AF. 2007. Target protectors reveal dampening and balancing of Nodal agonist and antagonist by miR-430. Science 318: 271-274.

Ebert MS, Sharp PA. 2010. MicroRNA sponges: Progress and possibilities. RNA 16: 2043-2050.

Ebert MS, Neilson JR, Sharp PA. 2007. MicroRNA sponges: Competitive inhibitors of small RNAs in mammalian cells. Nat Methods 4: 721-726.

Elbashir SM, Harborth J, Lendeckel W, Yalcin A, Weber K, Tuschl T. 2001. Duplexes of 21-nucleotide RNAs mediate RNA interference in cultured mammalian cells. Nature 411: 494-498.

Farrell PJ, Sen GC, Dubois MF, Ratner L, Slattery E, Lengyel P. 1978. Interferon action: Two distinct pathways for inhibition of protein synthesis by double-stranded RNA. Proc Natl Acad Sci 75: 58935897.

Fedorov Y, Anderson EM, Birmingham A, Reynolds A, Karpilow J, Robinson K, Leake D, Marshall WS, Khvorova A. 2006. Off-target effects by siRNA can induce toxic phenotype. RNA 12: 1188-1196.

Gantier MP, Williams BRG. 2009. siRNA delivery not Toll-free. Nat Biotechnol 27: 911-912.

Haraguchi T, Ozaki Y, Iba H. 2009. Vectors expressing efficient RNA decoys achieve the long-term suppression of specific microRNA activity in mammalian cells. Nucleic Acids Res 37: e43. doi: 10.1093/ nar/gkp040.

Heil F, Hemmi H, Hochrein H, Ampenberger F, Kirschning C, Akira S, Lipford G, Wagner H, Bauer S. 2004. Species-specific recognition of single-stranded RNA via toll-like receptor 7 and 8. Science 303: 1526-1529.

Jackson AL, Bartz SR, Schelter J, Kobayashi SV, Burchard J, Mao M, Li B, Cavet G, Linsley PS. 2003. Expression profiling reveals off-target gene regulation by RNAi. Nat Biotechnol 21: 635-637.

Kang D, Gopalkrishnan RV, Wu Q, Jankowsky E, Pyle AM, Fisher PB. 2002. mda-5: An interferon-inducible putative RNA helicase with double-stranded RNA-dependent ATPase activity and melanoma growth-suppressive properties. Proc Natl Acad Sci 99: 637-642.

Kanneganti T, Body-Malapel M, Amer A, Park JH, Whitfield J, Franchi L, Taraporewala ZF, Miller D, Patton JT, Inohara N, et al. 2006. Critical role for Cryopyrin/Nalp3 in activation of 
caspase-1 in response to viral infection and double-stranded RNA. J Biol Chem 281: 36560-36568.

Kim D, Behlke MA, Rose SD, Chang M, Choi S, Rossi JJ. 2005. Synthetic dsRNA Dicer substrates enhance RNAi potency and efficacy. Nat Biotechnol 23: 222-226.

Kleinman ME, Yamada K, Takeda A, Chandrasekaran V, Nozaki M, Baffi JZ, Albuquerque RJC, Yamasaki S, Itaya M, Pan Y, et al. 2008. Sequence- and target-independent angiogenesis suppression by siRNA via TLR3. Nature 452: 591-597.

Krützfeldt J, Rajewsky N, Braich R, Rajeev KG, Tuschl T, Manoharan M, Stoffel M. 2005. Silencing of microRNAs in vivo with 'antagomirs'. Nature 438: 685-689.

Manche L, Green SR, Schmedt C, Mathews MB. 1992. Interactions between double-stranded RNA regulators and the protein kinase DAI. Mol Cell Biol 12: 5238-5248.

Marques JT, Devosse T, Wang D, Zamanian-Daryoush M, Serbinowski P, Hartmann R, Fujita T, Behlke MA, Williams BRG. 2006. A structural basis for discriminating between self and nonself doublestranded RNAs in mammalian cells. Nat Biotechnol 24: 559-565.

McManus MT, Petersen CP, Haines BB, Chen J, Sharp PA. 2002. Gene silencing using micro-RNA designed hairpins. RNA 8: 842-850.

Nallagatla SR, Hwang J, Toroney R, Zheng X, Cameron CE, Bevilacqua PC. 2007. 50-triphosphate-dependent activation of PKR by RNAs with short stem-loops. Science 318: 1455-1458.

Olejniczak M, Galka P, Krzyzosiak WJ. 2010. Sequence-non-specific effects of RNA interference triggers and microRNA regulators. Nucleic Acids Res 38: 1-16.

Paddison PJ, Caudy AA, Bernstein E, Hannon GJ, Conklin DS. 2002. Short hairpin RNAs (shRNAs) induce sequence-specific silencing in mammalian cells. Genes Dev 16: 948-958.

Reynolds A, Anderson EM, Vermeulen A, Fedorov Y, Robinson K, Leake D, Karpilow J, Marshall WS, Khvorova A. 2006. Induction of the interferon response by siRNA is cell type- and duplex length-dependent. RNA 12: 988-993.

Robbins M, Judge A, Ambegia E, Choi C, Yaworski E, Palmer L, McClintock K, MacLachlan I. 2008. Misinterpreting the therapeutic effects of small interfering RNA caused by immune stimulation. Hum Gene Ther 19: 991-999.

Robbins M, Judge A, MacLachlan I. 2009. siRNA and innate immunity. Oligonucleotides 19: 89-102.
Roberts WK, Clemens MJ, Kerr IM. 1976. Interferon-induced inhibition of protein synthesis in L-cell extracts: An ATP-dependent step in the activation of an inhibitor by double-stranded RNA. Proc Natl Acad Sci 73: 3136-3140.

Rossi JJ. 2009. Innate immunity confounds the clinical efficacy of small interfering RNAs (siRNAs). Gene Ther 16: 579-580.

Sabbah A, Chang TH, Harnack R, Frohlich V, Tominaga K, Dube PH, Xiang Y, Bose S. 2009. Activation of innate immune antiviral responses by NOD2. Nat Immunol 10: 1073-1080.

Samarajiwa SA, Forster S, Auchettl K, Hertzog PJ. 2009. INTERFEROME: The database of interferon regulated genes. Nucleic Acids Res 37: D852-D857.

Schlee M, Hartmann G. 2010. The chase for the RIG-I ligand-recent advances. Mol Ther 18: 1254-1262.

Shukla S, Sumaria CS, Pradeepkumar PI. 2010. Exploring chemical modifications for siRNA therapeutics: A structural and functional outlook. ChemMedChem 5: 328-349.

Silva JM, Li MZ, Chang K, Ge W, Golding MC, Rickles RJ, Siolas D, Hu G, Paddison PJ, Schlabach MR, et al. 2005. Second-generation shRNA libraries covering the mouse and human genomes. Nat Genet 37: 1281-1288.

Siolas D, Lerner C, Burchard J, Ge W, Linsley PS, Paddison PJ, Hannon GJ, Cleary MA. 2005. Synthetic shRNAs as potent RNAi triggers. Nat Biotechnol 23: 227-231.

Sioud M. 2009. Deciphering the code of innate immunity recognition of siRNAs. Methods Mol Biol 487: 41-59.

Tsuda N, Mine T, Ioannides CG, Chang DZ. 2009. Synthetic microRNA targeting glioma-associated antigen-1 protein. Methods $\mathrm{Mol}$ Biol 487: 435-449.

Yang S, Tutton S, Pierce E, Yoon K. 2001. Specific double-stranded RNA interference in undifferentiated mouse embryonic stem cells. Mol Cell Biol 21: 7807-7816.

Zeng Y, Wagner EJ, Cullen BR. 2002. Both natural and designed micro RNAs can inhibit the expression of cognate mRNAs when expressed in human cells. Mol Cell 9: 1327-1333.

Zhang F, Romano PR, Nagamura-Inoue T, Tian B, Dever TE, Mathews MB, Ozato K, Hinnebusch AG. 2001. Binding of double-stranded RNA to protein kinase PKR is required for dimerization and promotes critical autophosphorylation events in the activation loop. J Biol Chem 276: 24946-24958. 

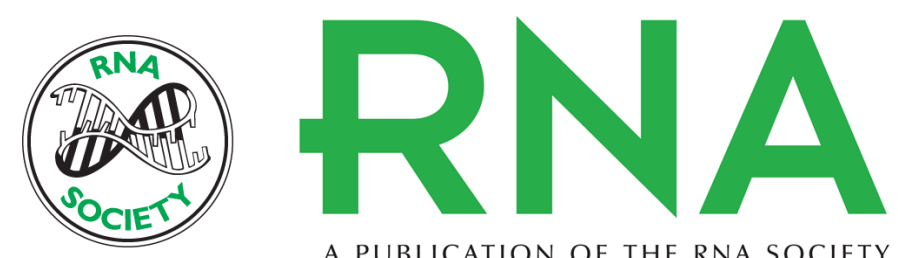

A PUBLICATION OF THE RNA SOCIETY

\section{RNAimmuno: A database of the nonspecific immunological effects of RNA interference and microRNA reagents}

Marta Olejniczak, Paulina Galka-Marciniak, Katarzyna Polak, et al.

RNA 2012 18: 930-935 originally published online March 12, 2012

Access the most recent version at doi:10.1261/rna.025627.110

Supplemental http://rnajournal.cshlp.org/content/suppl/2012/02/27/rna.025627.110.DC1
Material

References This article cites 44 articles, 17 of which can be accessed free at: http://rnajournal.cshlp.org/content/18/5/930.full.html\#ref-list-1

Open Access Freely available online through the RNA Open Access option.

License Freely available online through the RNA Open Access option.

Email Alerting Receive free email alerts when new articles cite this article - sign up in the box at the Service top right corner of the article or click here.

To subscribe to RNA go to:

http://rnajournal.cshlp.org/subscriptions 